\title{
Contemporary Condition of the Irrigative Soils in
}

\section{Mugan-Salyan Massif}

\author{
Mustafayev Mustafa Gilman \\ Institute of Soil Science and Agrochemistry of ANAS, Baku, Azerbaijan
}

\begin{abstract}
The article deals with the information on saline soils of the irrigated land in Mugan-Salyan massif and their appearance reasons. During the study, changes in the physical properties of water, land drainage, groundwater level, mineralization, soil salinity of this territory have been investigated as well. Studies show that in the current territory elevated levels of ground water in drainage and irrigation networks, revealed that their mineralization and the amount of salts in the soil were under bad condition. On the basis on studies measurements for soils state in Mugan-Salyan massif have been presented.
\end{abstract}

Key words: Granulometric composition, physical clay, humus, absorption capacity, soil salinization.

\section{Introduction}

Saline soils in Azerbaijan extend mainly Kur-Araz lowland and affect the Republic's economy. Within it the main areas of cotton and other crops grow. Due to the salinity of soils in ground layer development in irrigated agriculture in Kur-Araz lowland on its first step has encountered with melioration work. The very significant interest to reclamation of saline soils in the Kur-Araz lowland puts forward some questions about the origin of the huge salts amount contained in the soil, sediments and groundwater.

As it is known, in the irrigated agriculture, the reason of the salinization comes generally from poor drainage which causes the presence of salts in the soils. Irrigation redistributes chiefly salt reserves that exist in the soil. Observations of the salt regime of irrigated soils in the drained areas showed that in the presence of waterproof densified horizon $\mathrm{BT}_{\mathrm{S}}$ - at $25-40 \mathrm{~cm}$ depths and strong soil salinization relates with the irrigation water norms, which has been contributed to the displacement of the lower layers of salt and salt-enhanced upper soil (BTs - textures-brown color, nut-shaped structure, granulometric composition of the

Corresponding author: Mustafayev Mustafa Gilman, Dr., associate professor, research fields: soil science, soil reclamation. clay, dusty-clay, irons-clay, humus-clay, easy water-soluble salts containing layer).

Stocks of soluble salts are one of the main criteria for the evaluation of agricultural soils in dry areas. Evaluation of soils with respect to their degree of salinity is not applicable to such areas characteristic is soil cover. In a shallow bay of the ancient Caspian Sea, the site where Mugan plain was formed, the repeated regression contributed to the huge accumulation of salts in the sediment and sediment shoreline. Kovda's [1] calculations show that only in the northern part of the Caspian lowlands (on 120,000 $\mathrm{km}^{2}$ area) can latest transgression of the Caspian Sea consist probably of near $2.5 \times 10^{3} \mathrm{~m}$ salts, where $40 \%$ happens due to chlorides.

According to modern views, reclamation of saline soils can not be studied only by application of modern universal technical devices. This requires the implementation of an integrated system of measurements related with and consisting of the following elements:

(a) high agronomic complexes;

(b) appropriate territory organization;

(c) the correct irrigation network use;

(d) a set of special reclamation measures to remove salts from the soil. 
The first three elements are known to be systemic forms of action that prevent salt accumulation in the soil, which is very important in dealing with secondary salinity. However, in those cases where the soils are highly saline (or salt marshes) for the improvements made to the main method is the fourth element of the forms of action, that is capital flushing has been planned on the background of collector-drainage system.

In the development of soil salinity of Mugan-Salyan Massif the major role concerns to the irrigation. As a means of irrigation flood of large areas with excessive water amounts, delaying irrigation duration was presented.

This has been realized to rapid ascending grade of the ground water level by following salinization intensity. Since 1950 year in Mugan-Salyan territory collector-drainage network building on a large scale has begun. The effectiveness of all meliorative measures resulted in thorough study.

Results of salt filming and monitoring groundwater levels in most of the cases showed that sustainable desalination of soil and systematic reduction of the ground water level were achieve. Currently, not only the direct impact on soil reclamation should be learned, but also the influence of drainage on the whole eco-geographical landscape and resulting impact on processes in saline soils as well. Therefore, in terms of a market economy, it is necessary to pay close attention to the economic activities of man and especially the impact of land reclamation and irrigation on the environment. This allows you to predict the impact of land reclamation and to avoid agricultural production processes.

The above mentioned allows us to say that human activity is a powerful environmental factor affecting the soil and vegetation. Study of the effects of this exposure may increase productivity of the soil used for agricultural crops.

In this regard, we have studied the change of soil salinity and groundwater salinity Mugan-Salyan array and present comprehensive event for the reclamation of the land.

\section{Materials and Methods}

Reseach investigations were carried out on reclaimed land of Mugan-Salyan array. The total area of the array Mugan- Salyan is 871.1 hectares. The slope of the relief is directed from south-west to north-east and to the Caspian Sea and ranges from 0.0008 to 0.001 . Parent rocks are marine deposits of the Kur and Araz.

In the design of irrigation and drainage systems data on irrigation to the norm, the number of irrigation, irrigation norms and values of inter-irrigation interval productivity by type of irrigated crops were used as starting information. For the land found in Mugan-Salyan array characteristic is very common saline soils. Therefore, the explanation of the genesis of salinity, its features, the patterns of change in salinity within individual districts and Mugan-Salyan steppe is a very important task to solve the practical problems of reclamation of the land. With respect to salinity Mugan-Salyan steppe and the least South Mugan sloping plain should be noted as the most salted land. Salinity of/in North Mugan is very colorful: at close distance of range from large irrigation canals there is ground with salt content of less than $0.50 \%$ of solid residue, and the remote locations of the channels with a salt content of $2.0 \%$ in the $0-100 \mathrm{~cm}$ more salted Western North Mugan and more favorable with regard to soil salinity eastern North Mugan, the so-called "Chal region".

Mugan-Salyan geology of the array is connected with the general history of geotectonic area around the Caspian Sea. The whole history of the array is, in essence, the struggle of land and sea, which resulted in the sea with more and more retreats. Repeated transgressions and regressions of the Caspian Sea resulted in the lowlands of the alternation of marine sediments. Caspian deposits throughout North Mugan overlap alluvial Kur and Araz reaching capacity of 10-20 m, the thickness of alluvial different diversity of its composition and variability in both the horizontal 
and in the vertical direction. In the most general form of the surface of the device Mugan-Salyan steppes can be represented as a broad concave tray, raised in the rear and to the sides, and open to the south- east, to the Caspian Sea. Mugan steppe around through the collector of the Lenin irrigation system is divided into North and South and Central Mugan.

Mugan-Salyan climate array Figurovsky [2] was named subtropical dry, Berg [3] is related to the non-tropical desert climate. Volobuev [4] pointed out that the climate concerning the area is transitional nature and with the greatest reason should determine its sub-tropical semi-desert. Shikhlinski [5] based on the energy indicators and noted that the exchange of landscape and climate, the Kur-Araz lowland is classified as semi-subtropical zone. The average annual temperature is equal to the average for Mugan $+14.0{ }^{\circ} \mathrm{C}$ for Salyan $+14.0-14.2{ }^{\circ} \mathrm{C}$, and for Zyud-Ost-Kultuk $-14.9{ }^{\circ} \mathrm{C}$. In general, the average annual temperature above the sea level to the east and no west is the same. The coldest is January $-1.5-2.0{ }^{\circ} \mathrm{C}$ for Mugan, $2.2{ }^{\circ} \mathrm{C}$ to $4.3{ }^{\circ} \mathrm{C}$ Salyan and for the Zyud-Ost-Kultuk, and the warmest July and August 26.5-26 and $3{ }^{\circ} \mathrm{C}$ for Mugan, 26.4-26.0 ${ }^{\circ} \mathrm{C}$ Zyud-Ost-Kultuk. The amount of average annual precipitation is 246 to Mugan and Salyan to $237 \mathrm{~mm}$ and rarely exceeds $300 \mathrm{~mm}$. The number of days with precipitation for the Mugan-Salyan array is 60-62 days. The highest rainfall is confined to the autumn-winter period, and the least for the summer. Relative humidity in the coastal zone is much higher ( $79 \%$ higher than in all other places $70-75 \%$ ). Evaporation from water surface and Mugan-Salyan structure respectively reaches 950 and $940 \mathrm{~mm}$, which is several times higher than the usual rainfall. Therefore, the surface layers of the soil in those most attractive years, have sharply negative water balance, which is shallow with saline groundwater creates the conditions for the progressive salinization of the soil profile.

On Mugan-Salyan array grey meadow soils (Cleyis Calcisols) mostly extend. Under the influence of different intensity in the wet, alluvial soils are formed by a number of meadow like light meadow, dark meadow, marsh and meadow marsh. Gray soils are more pronounced profile, especially in the coloration of the humus horizon. For grey-brownish soil ordinary characteristic of high biological handles and clearly expressed rich micro structure. The distribution of carbonate is uneven. The maximum content of $\mathrm{CaCO}_{3}$ was noted in the horizon of the $\mathrm{BCA}$ onsiderable areas of gray soils of the Kur-Araz lowland are used for irrigated crops. (BCA - the layer the illuvial carbonates concentrate). Grey soils, with a small supply of humus and nutrients to and potential fertility are inferior to other types of semi-desert zone. Reserves of humus in the $0-20 \mathrm{~cm}$ layer are not more than $30-65 \mathrm{t} / \mathrm{ha}$, hydrolyzed nitrogen $100-150 \mathrm{mg} / \mathrm{kg}$ of digestible phosphorus 5-40, exchangeable potassium 200-400 $\mathrm{mg} / \mathrm{kg}$. Much of the grey desert soil used in irrigated agriculture is the main land fund for cotton and grains. Small tracts are busy with winter pastures [6].

Meadow-grey soils are formed under conditions of high soil moisture the surface there is shallow groundwater (2.5-3.0). The quantity of soil moisture greatly affects the soil profile, changes these soils, in particular in the development process and gley suppression quantity of oxidation-reductive process. Characteristically deep humus content in the horizon $\mathrm{A} / \mathrm{AB}(\mathrm{A} / \mathrm{AB}$ - Deep humic layer).

The humus content of $2.5-2.8 \%$ average change with a uniform decline with depth. The composition is mainly humus-fulvic. Carbonate formations in the form of "points" and mildew appear below the horizon $\mathrm{AB}$, deeper in the sun - whitish spots. Characteristic of meadow-gray soils is rusty ochrer spots in horizon-Sun. The reaction of the soil solution is neutral or sharply schelochnaya. Amount of $\mathrm{pH}$ ranges from 7.2-8.2. Particle size distributions, the profile of these soils are well to differentiate. Some of the high content of clay fraction $<0.001$ are noted in the horizon VT. These soils are heavy clay and clay. In respect of agricultural industrial meadow-gray soil, Kur-Araz lowland soils 
have high site quality and developed under irrigated crops.

Mugan-Salyan soil is characterized by an array of different particle size, from medium to heavy clay loam, sandy loam and sand layers. On the territory of Mugan-Salyan array two types of ground water regime were observed: the natural and the artificial. The first type is formed under the influence of infiltration water, precipitation, the rivers Kur and Araz large irrigation canals. The second type of ground water regime formed under irrigation. In the irrigated tracts ground water in the autumn and winter lie deep, and in the growing season they rise. In late summer and early autumn, fall again, and has been declining in the late autumn to maximum depths. Due to the rainfall, changes of ground water are not observed. Fluctuations here are in the range of $0.5 \mathrm{~m}$, whereas in the irrigated areas of the amplitude of the fluctuations of the water table 2 reaches 1.5-2.0 m. Patterns of distribution of the chemical composition of the soil water Mugan-Salyan array were characterized mainly by Kovda [1] and Volobuev [4]. These researchers within the array have chosen three main governmental water types: hydrocarbon, chloride and sulphate. In the Mugan steppe in the piedmont area of groundwater sulphate, pass below the contact area talus, alluvium from the Kur-Araz alluvium chloride in water. Mineralization sulphate water is higher than carbonate.

Especially high salinity differ sulfate groundwater at South Mugan, reaching up to $100 \mathrm{~g} / \mathrm{L}$ or higher. Chloride ground water is highly mineralized zone Khilli-Neftechala where there are dozens of grams of salt per liter, sometimes the same exceptionally high above $100 \mathrm{~g} / \mathrm{L}$. The high salinity of groundwater is due to the fact that these sites are places of their most intense evaporation, as well as feeding them with deep artesian waters. According to the degree of soil salinity it is depending on the amount of salt and salt-depth horizons. It is believed that if the soil horizon contains less than $0.25 \%$ of soluble salts, it is a non-saline $0.25-0.50 \%$ weakly, $0.50-1.00 \%$ average; $1.00-2.00 \%$ strongly, very strongly $2.00-3.00 \%$ and $3.00 \%$ more-salt marsh [7]. When studying changes in soil salinity we are using the above grades.

Water extract of soil samples and groundwater drainage water is determined by the usual of method Arinushkina [8] ions $\mathrm{CO}_{3}$ and $\mathrm{HCO}_{3}$ by titration with sulfuric acid, $\mathrm{Cl}$-argentiometricheskim by Mora, the sum of $\mathrm{Ca}$ and $\mathrm{Mg}$-trilonometric; $\mathrm{SO}_{4}$-volume and $\mathrm{Na}$ $+\mathrm{K}$ - the difference between the sum of cations and anions. Capacity weight of the soil is determined by the method of Kachinski [9], specific weight to Dolgova method, particle size distribution to the method of the pipette with the processing of $1.0 \mathrm{NaCI}$; humus method Tyurin, pH-potentiometric. The composition of the absorption-saturated grounds has been determined by extraction from the soil $\mathrm{Ca}$ and $\mathrm{Mg}$ absorbed by the method Ivanova; reference sodium by Gedroys.

\section{Results and Discussion}

Saline soils of Mugan-Salyan are distinguished array of salts on the composition and the degree of salinity. In the separation of the com-position of salts it is accounted mainly by their anions. Therefore, the basis to distinguish between salinity soda-sulfate, chloride-sulphate (with the predominance of chlorides, sulfates above), sulfate-chloride (with a predo-minance of chlorides (sodas) sulfate), and finally, with the chlorine. Cases of nitrate salinity are very rare, and related soils occupy a very small space.

In the above list of types of soil salinity ascending order of aridity is placed and increasing salinity of groundwater, i.e. dominated by soil sulphate-soda-salinity on low-mineralized ground-water with good drainage, in the most arid climate, soil chloride salinity with strong mineralized waters have poor drainage.

Mugan-Salyan in the array irrigation has the most significant influence both on the water and in the salt regime of soils. Redistribution of soluble salts in the soil profile depends on a number of factors such as initial deposits of salt, salinity of irrigation water depth 
and salinity of groundwater.

The study of the nature of soil salinity of the Kur-Araz lowland subject of numerous studies of the Institute of Soil Science and Agricultural Chemistry of the NAS of Azerbaijan, Soil Science Institute named after Dokuchaev and the Institute "Azgiprovodhoz." Significant contribution to the compilation of the research was introduced by Volobuyev [7], which was for the Kur-Araz lowland maps of salinity and salt content of soils and soil-geochemical maps showing the content in the soils of the individual components of the salt composition.

Some researchers have conducted more research, resulting in more detailed maps drawn up on parts of the lowlands $[10,11]$.

In saline soil talus plains of Azerbaijan with the divide-trivial form of salinization should consider the effect of irrigation water. Many researchers were studying the impact of irrigation on the process of salinization and soil desalination [12-15].

As you know, in irrigated agriculture resulted in the salinization of soils, especially in onditions of poor drainage, there is not so much solution, and the presence of salts in the soils before irrigation. Irrigation mainly determines the salt reserves which exist in the soil.

Height of the subsoil waters and their basically mineralization cause an increase of the subsoil waters evaporation consumption and restore to the secondary salinization of the irrigated soils everywhere.

Our longstanding work adequately elucidates the relation of secondary salinization of soils with a primary natural salinity and different sides of human activities, and also shows a certain stage in the forms of manifestation of secondary salinization of irrigated lands.

The analysis of groundwater salinity and soil salinity in the territory of Mugan-Salyan array shows that it is more diverse, relevant, mainly the outcome of character strength of soil salinity, drainage, topography, groundwater dynamics. For this purpose, conducted research on irrigated soils Mugan-Salyan array and found that, due to improper conduct irrigation and adequate condition of the drainage system, the number of salts, groundwater salinity, and their occurrence is higher, than in other areas.

During the research in this area was laid about 40 cuts at a depth of 1.5-2.0 $\mathrm{m}$ from the results of the analysis which were grouped according to the classification of salinity (Table 1) by Volobuyev [7] are

Table 1 Amount of salts (\%) and groundwater salinity (g/l) on meadow-gray soils Mugan-Salyan array.

\begin{tabular}{|c|c|c|c|c|c|c|c|c|c|c|}
\hline $\begin{array}{l}\text { Stage of } \\
\text { saline soil }\end{array}$ & $\begin{array}{l}\text { Depth, } \\
\text { m }\end{array}$ & $\begin{array}{l}\text { Physical } \\
\text { cley }(< \\
0.01)\end{array}$ & $\begin{array}{l}\text { Specific } \\
\text { weight, } \\
\mathrm{g} / \mathrm{cm}^{3}\end{array}$ & $\begin{array}{l}\text { Bulk } \\
\text { desnity, } \\
\mathrm{g} / \mathrm{cm}^{3}\end{array}$ & $\begin{array}{l}\text { Porosity, } \\
\%\end{array}$ & $\begin{array}{l}\text { Whole } \\
\text { field wa-ter } \\
\text { capa-city, \% }\end{array}$ & $\mathrm{pH}$ & $\begin{array}{l}\text { Hu-mus } \\
\text { content, \% }\end{array}$ & $\begin{array}{l}\text { Sum of the } \\
\text { absorbed basis, } \\
\text { (SAB) } \\
\text { mg.ekv }\end{array}$ & $\begin{array}{l}\mathrm{Na} \text {-from } \\
\mathrm{SAB}, \%\end{array}$ \\
\hline \multirow{6}{*}{$\begin{array}{l}\text { Weak } \\
\text { saline soil }\end{array}$} & $0-20$ & 47.60 & 2.51 & 1.22 & 51 & 42 & 7.7 & 2.45 & 29.30 & 6.15 \\
\hline & $20-40$ & 46.84 & 2.53 & 1.24 & 51 & 41 & 7.7 & 1.58 & 25.97 & 6.17 \\
\hline & $40-60$ & 50.20 & 2.55 & 1.27 & 50 & 39 & 7.6 & 1.09 & 30.95 & 5.49 \\
\hline & $60-80$ & 37.76 & 2.57 & 1.30 & 49 & 38 & 7.5 & 0.87 & 21.77 & 6.43 \\
\hline & $80-100$ & 35.32 & 2.59 & 1.34 & 48 & 36 & 7.6 & 0.67 & 22.05 & 5.90 \\
\hline & $100-200$ & 43.84 & 2.62 & 1.36 & 48 & 35 & 7.7 & 0.60 & 23.52 & 6.20 \\
\hline \multirow{6}{*}{$\begin{array}{l}\text { Medium } \\
\text { saline soil }\end{array}$} & $0-20$ & 58.36 & 2.65 & 1.39 & 48 & 34 & 7.8 & 2.39 & 26.13 & 7.66 \\
\hline & $20-40$ & 56.72 & 2.66 & 1.41 & 47 & 33 & 7.8 & 1.45 & 23.55 & 7.65 \\
\hline & $40-60$ & 53.44 & 2.67 & 1.43 & 46 & 32 & 7.9 & 1.00 & 24.15 & 7.86 \\
\hline & $60-80$ & 55.24 & 2.69 & 1.46 & 46 & 31 & 7.6 & 0.78 & 23.57 & 7.12 \\
\hline & $80-100$ & 52.60 & 2.71 & 1.48 & 45 & 30 & 7.9 & 0.61 & 22.67 & 7.94 \\
\hline & $100-200$ & 50.96 & 2.72 & 1.52 & 44 & 29 & 7.8 & 0.50 & 21.80 & 7.85 \\
\hline \multirow{6}{*}{$\begin{array}{l}\text { Strong } \\
\text { saline soil }\end{array}$} & $0-20$ & 64.80 & 2.67 & 1.38 & 48 & 35 & 8.2 & 0.95 & 31.75 & 14.90 \\
\hline & $20-40$ & 66.24 & 2.68 & 1.43 & 47 & 33 & 8.4 & 0.81 & 32.55 & 16.30 \\
\hline & $40-60$ & 60.22 & 2.70 & 1.45 & 46 & 32 & 8.2 & 0.65 & 31.10 & 12.40 \\
\hline & $60-80$ & 67.80 & 2.72 & 1.48 & 45 & 30 & 8.6 & 0.58 & 34.60 & 19.64 \\
\hline & $80-100$ & 60.90 & 2.73 & 1.51 & 44 & 29 & 8.1 & 0.48 & 30.97 & 11.90 \\
\hline & $100-200$ & 58.92 & 2.72 & 1.54 & 43 & 28 & 8.0 & 0.35 & 28.50 & 10.50 \\
\hline
\end{tabular}


widely used in our country. The research shows that the number of salts in the soil profile and its different rates increase from the upper to the lower soil. This process clearly expresses where the drainage system is working properly. The research shows that, in non-saline soil to a depth of $0-100 \mathrm{~cm}$ salts varies between $0.130-0.246 \%$ and $100-200 \mathrm{~cm}, 0.115-0.289 \%$; groundwater salinity ranging from 1.20 to $2.80 \mathrm{~g} / \mathrm{L}$. The results show that, on a weakly saline soils, these figures vary between $0.265-0.448 \%, 0.218-0.410 \%$ and $2.90-4.50 \mathrm{~g} / \mathrm{L}$.

At medium-saline soils, these figures vary from $0.526-0.895 \%$, respectively; $0.213-0.903 \%$ and 2.50-4.6 g/L in highly saline soils: $1.356-1.803 \%$ and $0.435-2.363 \%, 4.80-8.60 \mathrm{~g} / \mathrm{L}$; very strongly saline soils: $2.107-2.790 \%, 1.474-1.639 \%$ and $8.20-8.50 \mathrm{~g} / \mathrm{L}$, the salt marshes: $3.212-4.480 \%, \quad 2.199-4.005 \%$, 20.860-29.905 g/L. For the study of the current state of soil Mugan-Salyan array conducted complex investigations.

To do this, on this territory were selected key areas that have varying degrees of salinity and determined their key performance indicators. The result shows the profile of different indicators. So, for example by slightly saline soils, the number of physical clay varies between $35.32-50.20 \%$, the share of $2.51-2.62 \mathrm{~g} / \mathrm{cm}^{3}$ bulk density of $1.22-1.36 \mathrm{~g} / \mathrm{cm}^{3}$, porosity of $51-48 \%$ total moisture content $42-35 \%, \mathrm{pH}$ 7.5-7.7, humus 2.45-0.60\%, the amount of absorbed bases 21.77-30.95 mg.ekv and $\mathrm{Na}-5.90-6.43 \%$ (Table 1).

Table 1 shows that the greater the amount of salt where there are strong indicators of these changes. And where there is a high salinity, $\mathrm{pH}$ ranges from 7.6-8.6; humus 2.39-0.35\%; Na-7.12-19.64\%; physical clay $50.96-67.80 \%$; share of $1.38-1.54 \mathrm{~g} / \mathrm{cm}^{3}$, and the bulk density varies $2.65-2.73 \mathrm{~g} / \mathrm{cm}^{3}$. The number of total porosity and moisture content on the contrary reduced. The Table 1 shows that in this area the porosity parameters vary in the range $48-43 \%$, and the total moisture content of the soil from 35 to $28 \%$.

As a result of a comprehensive study we have identified various areas of saline soils (hectares and $\%$-s), drainage, groundwater levels, and the area of mineralization at grades were generally evaluated the reclamation of irrigated soils Mugan-Salyan array [16].

Stocks of soluble salts are one of the most important criteria for the evaluation of agricultural soils in dry areas. Evaluation of soils with respect to their degree of salinity for such areas is an indispensable characteristic of the soil cover. It is no accident that the assessment of the degree of soil salinity was the first characteristic of saline soils in respect of which have been applied quantitative criteria [16-18].

The data revealed by the studies on the salinity hallow water Table 2 and salinity are shown in the tables below (see Tables 3 and 4). As can be seen from the tables in heavily irrigated soils with poor drainage work on the salinization of soils in varying stages.

It is evident from Table 4 in Mugan-Salyan array with non-saline soils is 125,650 hectares or $14.42 \%$ with total area.

Slightly saline soils are 272,070 ha $(31.23 \%)$, moderately saline $-210,560$ ha $(24.17 \%)$, highly saline 125,850 ha $(14.45 \%)$, very strongly saline 109,450 ha $(12.57 \%)$ and saline-27,520 ha (3.16\%). On the territory of the array the area 233,395 ha has a system of open and closed drains. Of these, an area of 211,084 hectares or $90.45 \%$ is constructed open drains an area of 22,311 ha or $9.55 \%$ horizontal closed drains. Despite the fact that the Mugan-Salyan array of $85.58 \%$ or 745,450 hectares are affected by salinity to varying degrees. As the data on salinity and depth of ground water in irrigated areas Mugan-Salyan array rated as good $-10,216$ ha, or $4.05 \%$, satisfactory-178,983 ha or $70.88 \%$, unsatisfactory- 63,301 ha or $25.07 \%$ (Table 3).

Results of the study show that the poor performance of the drainage system and the high salinity of groundwater friction demanded the fix drainage system and the activities directed at reducing groundwater salinity. Effect of irrigation on changes in the properties and fertility of soil is found, depending on the initial soil and hydrogeological conditions of the 
Table 2 Come parameters of the irrigated serozem soils in the Mugan-Salyan massive.

\begin{tabular}{|c|c|c|c|c|}
\hline \multirow{3}{*}{ Incision place } & \multicolumn{2}{|c|}{ Depth } & \multirow{3}{*}{$\begin{array}{l}\text { - Depth of the ground water, } \\
-\mathrm{m}\end{array}$} & \multirow{3}{*}{$\begin{array}{l}\text { Mineralization of ground } \\
\text { water, } g / L\end{array}$} \\
\hline & \multicolumn{2}{|c|}{ Amount of salt, $\%$} & & \\
\hline & $0-100 \mathrm{~cm}$ & $100-200 \mathrm{~cm}$ & & \\
\hline \multirow{8}{*}{$\begin{array}{l}\text { Nonsaline soil } \\
(<0.25 \%)\end{array}$} & 0.130 & 0.115 & 3.00 & 1.2 \\
\hline & 0.140 & 0.144 & 2.95 & 1.5 \\
\hline & 0.217 & 0.214 & 2.70 & 2.5 \\
\hline & 0.220 & 0.278 & 2.75 & 2.6 \\
\hline & 0.221 & 0.289 & 2.60 & 2.8 \\
\hline & 0.208 & 0.138 & 2.95 & 1.4 \\
\hline & 0.169 & 0.176 & 2.80 & 1.8 \\
\hline & 0.246 & 0.265 & 2.65 & 2.6 \\
\hline \multirow{5}{*}{$\begin{array}{l}\text { Weak saline soil } \\
(0.25-0.50 \%)\end{array}$} & 0.265 & 0.285 & 2.20 & 3.2 \\
\hline & 0.415 & 0.218 & 2.62 & 2.9 \\
\hline & 0.356 & 0.334 & 2.40 & 3.5 \\
\hline & 0.448 & 0.380 & 2.30 & 3.9 \\
\hline & 0.442 & 0.410 & 2.25 & 4.5 \\
\hline \multirow{5}{*}{$\begin{array}{l}\text { Medium saline soil } \\
(0.50-1.0 \%)\end{array}$} & 0.779 & 0.903 & 2.30 & 3.9 \\
\hline & 0.597 & 0.348 & 2.60 & 2.6 \\
\hline & 0.526 & 0.213 & 2.55 & 2.5 \\
\hline & 0.685 & 0.439 & 2.42 & 3.5 \\
\hline & 0.895 & 0.675 & 2.25 & 4.8 \\
\hline \multirow{8}{*}{$\begin{array}{l}\text { Strong saline soil } \\
(1-2 \%)\end{array}$} & 1.803 & 0.435 & 2.20 & 4.8 \\
\hline & 1.665 & 1.170 & 2.10 & 5.2 \\
\hline & 1.325 & 0.694 & 2.20 & 4.5 \\
\hline & 1.848 & 1.146 & 2.05 & 5.3 \\
\hline & 1.434 & 0.638 & 2.15 & 4.8 \\
\hline & 1.624 & 2.341 & 1.85 & 7.9 \\
\hline & 1.628 & 2.345 & 1.80 & 8.5 \\
\hline & 1.506 & 2.363 & 1.75 & 8.6 \\
\hline \multirow{6}{*}{$\begin{array}{l}\text { Higher saline soil } \\
(2-3 \%)\end{array}$} & 2.402 & 1.751 & 1.72 & 9.5 \\
\hline & 2.107 & 1.474 & 1.70 & 9.4 \\
\hline & 2.734 & 1.639 & 1.70 & 9.5 \\
\hline & 2.531 & 1.476 & 1.75 & 9.3 \\
\hline & 2.790 & 1.503 & 1.70 & 9.2 \\
\hline & 2.217 & 1.543 & 1.70 & 9.3 \\
\hline \multirow{8}{*}{$\begin{array}{l}\text { Alkaline lands } \\
(>3.0)\end{array}$} & 3.272 & 2.999 & 1.50 & 20.864 \\
\hline & 3.212 & 3.225 & 1.45 & 21.540 \\
\hline & 4.480 & 4.005 & 1.20 & 29.905 \\
\hline & 4.395 & 3.975 & 1.30 & 27.840 \\
\hline & 4.420 & 3.820 & 1.25 & 28.220 \\
\hline & 4.375 & 3.680 & 1.30 & 27.950 \\
\hline & 3.625 & 3.432 & 1.40 & 24.420 \\
\hline & 3.820 & 3.510 & 1.35 & 25.810 \\
\hline
\end{tabular}

Table 3 The reclamation of irrigated lands Mughal-Salyan array (2000-2010 years).

\begin{tabular}{|c|c|c|c|c|c|c|c|c|c|c|}
\hline \multirow{2}{*}{$\begin{array}{l}\text { Total area, } \\
\text { ha }\end{array}$} & \multirow{2}{*}{$\begin{array}{l}\text { Irrigated } \\
\text { soils, } \\
\text { ha }\end{array}$} & \multicolumn{3}{|c|}{$\begin{array}{l}\text { Areas on the occurrence depth } \\
\text { of ground water level, } \mathrm{m}\end{array}$} & \multicolumn{3}{|c|}{$\begin{array}{l}\text { Area on ground water } \\
\text { mineralization, } \\
\mathrm{g} / \mathrm{L}\end{array}$} & \multicolumn{3}{|c|}{$\begin{array}{l}\text { Area estimation on level occurrence and } \\
\text { ground water mineralization }\end{array}$} \\
\hline & & $<1.0$ & $1.0-3.0$ & $>3.0$ & $<1.0$ & $1.0-3.0$ & $>3.0$ & Good & Satisfactory & Unsatisfactory \\
\hline \multirow{2}{*}{871,100} & \multirow{2}{*}{252,500} & 9,815 & $\underline{236,512}$ & $\underline{6,173}$ & $\underline{37,813}$ & $\underline{123,699}$ & $\underline{90,988}$ & $\underline{10,216}$ & 178,983 & $\underline{63,301}$ \\
\hline & & 3.89 & 93.67 & 2.44 & 14.97 & 48.99 & $\overline{36.04}$ & 4.05 & 70.88 & 25.07 \\
\hline
\end{tabular}

irrigated areas, irrigation water quality, engineering level and condition of irrigation systems, the general culture of irrigated agriculture. Therefore, in the latter as there are examples of long-term preservation of favorable soil properties and modes, as well as examples of significant adverse changes in soil properties and their regimes, leading to a deterioration of soil fertility. 
Table 4 Data of the land draining and salinity in the Mugan-Salyan massive ( 2000-2010 years).

\begin{tabular}{|c|c|c|c|c|c|c|c|c|c|}
\hline \multirow{2}{*}{$\begin{array}{l}\text { General } \\
\text { area, } \\
\text { ha }\end{array}$} & \multicolumn{6}{|c|}{$\begin{array}{c}\text { Gradation salinification }(0-100 \mathrm{~cm}) \text {, } \\
\text { Also }\end{array}$} & \multicolumn{3}{|c|}{ Drain area } \\
\hline & Non-saline & Weak saline & $\begin{array}{l}\text { Medium } \\
\text { saline }\end{array}$ & $\begin{array}{l}\text { Strong } \\
\text { saline }\end{array}$ & $\begin{array}{l}\text { Stronger } \\
\text { saline }\end{array}$ & Solonchak & $\begin{array}{l}\text { General, } \\
\mathrm{Ha}\end{array}$ & Open drains & $\begin{array}{l}\text { Closed } \\
\text { drains }\end{array}$ \\
\hline 871,100 & $\frac{125,000}{14.42}$ & $\frac{272,070}{31.23}$ & $\frac{210,560}{24.17}$ & $\frac{125,850}{14.45}$ & $\frac{109,450}{12.57}$ & $\frac{27,500}{3.16}$ & 233,395 & $\frac{211,084}{90.45}$ & $\frac{22,311}{9.55}$ \\
\hline
\end{tabular}

Note: numerator-area, ha;

In denominator - area, with \%.

Important reasons leading to negative changes in soil under irrigation are: excessive irrigation rates, large losses of water in the supply and distribution network, and the fields where there is no artificial drainage or poor condition. This leads to the development of adverse water conditions, and promoting the rise of ground water in irrigated areas. With the latest series of highly related adverse irrigation salinization, water logging, soil alkalinity. Currently, about $58 \%$ of the irrigated soils of Mugan-Salyan array have an average and a strong degree of salinity and require the use of capital reclamation measures.

In order to mitigate and neutralize the effects of irrigation it needs negative complexes of different activities, many of which are well known, but for various reasons are not implemented or are under way in insufficient quantities. Complexes of these activities should be strictly differentiated from the specific soil reclamation and general environmental purpose. For the latest drainage on existing irrigation systems, the device of modern drainage systems in areas of new irrigation is one of the important measures to mitigate its adverse effects. Almost all the buildings on the irrigation system are in need of repair or reconstruction. On some built structures marked disparity of their type or the act of entering the project. Many bridges have adapter plates, so goes the collapse of slopes channels at the congress of bridges.

Closed drainage often fails to fulfill its mission for the following reasons: the head of water in the canals, their strong siltation, overgrown slopes and bottom channels of dense trees and shrubs and water-loving plants. For the same reasons, it is almost impossible to detect visually collector outputs. The absence of normal regulation of groundwater level leads to water-logging areas, and on such grounds as pastures. From the above it can be concluded that in a virtually complete lack of funding where maintenance work in-reclamation systems performed goes into disrepair, are destroyed. The above mentioned affects productivity. Particular impact on the productivity of the irrigated area: differences in individual years in the amount of rainfall and temperature conditions, which currently can not be said - a major influence [19, 20].

In connection with the above, it is necessary to redefine the concept of development of agriculture in the region regarding the use of irrigated land, set aside special funds for the reconstruction and operation of amelioration and irrigation systems.

\section{Conclusion and Recommendations}

(1) Studies have shown that depending on soil degradation Mugan-Salyan array change in their physico-chemical properties happens as follows: in the slightly saline soils, the proportion was 2.51-2.62 $\mathrm{g} / \mathrm{cm}^{3}$ and a bulk density of $1.22-1.36 \mathrm{~g} / \mathrm{cm}^{3}$, physical clay $(<0.01 \mathrm{~mm}) 35.32-50.02 \%$, the porosity of $48-51 \%$ full field moisture capacity of $35-42 \%$, pH 7.5-7.7, $2.45-0.60 \%$ humus amount of absorbed bases of $22.05-30.95 \mathrm{mg}$, largest $\mathrm{Na} 5.49-6.43 \%$ of the amount of absorption-saturated grounds. In the middle of saline soils, these figures changed accordingly: 2.65-2.72 $\mathrm{g} / \mathrm{cm}^{3}, \quad 1.39-1.52 \mathrm{~g} / \mathrm{cm}^{3}, \quad 50.96-58.36 \%, \quad 44-48 \%$, $29-34 \%, 7.6-7.8,2.39-0.50 \%, 21.80-26.13 \mathrm{~m} / \mathrm{ekv}$. and $7.12-7.94 \%$ and in the highly clogging-represented - these values were, respectively: $2.67-2.73 \mathrm{~g} / \mathrm{cm}^{3}, \quad 1.38-1.54 \mathrm{~g} / \mathrm{cm}^{3}, \quad 58.92-67.80 \%$, $43-48 \%, 28-35 \%, 8.0-8.3,0.95-0.35 \%, 28.50-34.60$ 
meq. and 10.50-19.64\%

(2) Estimate of the area under salinity levels and groundwater salinity showed that non-irrigated areas Mugan-Salyan array of 10,216 hectares of the area in good condition, 178,983 hectares in satisfactory and unsatisfactory in 63,301 hectares. Studies have shown that in the irrigated soils of an area of 236,512 hectares of ground water level is $1.0-3.0 \mathrm{~m}$. It was found that 90,988 hectares of the study area groundwater salinity is greater than $3.0 \mathrm{~g} / \mathrm{L}$, and the level of the groundwater is $1.0-2.0 \mathrm{~m}$, they are also characterized by a high content of salts $(>1.0-3.0 \%)$.

(3) It was found out that the total area of the array of Mugan-Salyan is 125,000 hectares which is non-saline, slightly saline in 272,070 hectares, 210,560 in hectares are medium salinity; 125,850 hectares are of highly-saline, 109,450 ha is saline soil salinization, and 27,500 hectares are of salt marsh. On the territory of the array where the salinity ranges from moderate to severe salinity agromeliorative are necessary to carry out activities that contribute to a reduction in the amount of salts .

\section{References}

[1] Abduyev, M. R. 1977. "Accelerated Clay Salt Marsh Reclamation of Azerbaijan.” Elm, Baku, 109.

[2] Averyanov, S. F. 1965. "Some of the Salinization Prevention of Irrigated Soils and Measures for to Combat with It in the European Part of the USSR." In Irrigated Agriculture in the European Part of the USSR, edited by Kolos. Moscow, 25-63.

[3] Azizov, K. Z. 2006. "Fluid and Electrolyte Balance of the Reclaimed Soil of the Kura-Araz Lowland and Scientific Analysis of the Results.” Elm, Baku, 260.

[4] Arinushkina, E. V. 1970. "Guidelines for Chemical Analysis of Soil-M.” Moscow State University, 488.

[5] Babaev, M. P., Jafarova, Ch. M., and Hasanov, V. 2006. "Modern Classification of Azerbaijan Soils." Elm, Baku, 360 .
[6] Berg, L. S. 1938. Basics Climatology. Uchpedgiz, L., $1-59$.

[7] Volobuev, V. R. 1963. "Soils and Climate." Azerbaijan Academy of Sciences. SSR. Baku, 320.

[8] Volobuev, V. R. 1965. "Genetical Forms of Soil Salinity Kur-Araz Lowland.” Baku, 246.

[9] Jabrailova, G. G. 2008. "The Study of the Dynamics of Groundwater and Foresight Water-Salt Regime in the Service Area Vilashchay Water-Storage Basin. Ecological State of the Environment." Collection of Scientific Papers 3: 401-5.

[10] Zaydelman, F. R. 1978. "Soil Improvement." MSU, 384.

[11] Kachinsky, N. A. 1965. "Soil Physics." Ear, 60-79.

[12] Kovda, V. A. 1968. "Water and Salt Balance Mestenosti and Irrigated Pochv. V Book: Arid Soils as Irrigation Development Area." Science, 532.

[13] Kostyakov, A. N. 1960. "Basement of Melioration." Selkhozgiz, Moscow, 633.

[14] Mozhayskiy, J. A., Dubenok, N. N., Zhelezyaka, V. I., Guse, T. M., and Tobratov, S. A. 2003. "Ecological Aspects of Irrigation in Terms of Man-Made Pollution. Ecological Aspects of Land Reclamation of the South-nonchernozem." University of Moscow, 74-122.

[15] Mustafaev, M. G. 2008. "Soil and Climatic Conditions Influence on Mugan-Salyan Array on Agricultural Production." Izvestiya and Agricultural Sciences 6 (3): 44-7.

[16] Mustafaev, M. G. 2009. "The Role of Soil Improvement Mughal-Salyan Array." Mat. Intl. narod. konf. "Irrigation and Water Management XXI Century." Science and Education. Gorki, 41-5.

[17] Mustafaev, M. G. 2012. "Water and Physical Characteristics of Irrigated Soils in the Massif of Mugan-Salyan." Polish Academy of Sciences, Committee for Land Reclamation Journal of Water and Land Evelopment and Environmental Engineering in Agriculture, Water Land Development, PL ISSN 1429-7426, No. 17 (VII-XII). Polsha, 61-7.

[18] Rode, A. A. 1978. "Questions on Soil Water Regime." Gidrometoizdat, 211.

[19] Figurovsky, I. V. 1936. "Climate Zoning of Azerbaijan." Material for Climate Zoning of Azerbaijan SSR 4: 3-17.

[20] Shihlinsky, E. M. 1968. "Climate of Azerbaijan." AN Azerbaijan SSR, Baku, 12-65 